\title{
EUS-guided fiducial placement for pancreatobiliary malignancies: safety, infection risk, and use of peri-procedural antibiotics
}

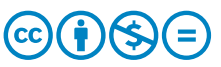

\author{
Authors \\ Madhuri Chandnani, Mir Fahad Faisal, Jeremy Glissen-Brown, Mandeep Sawhney, Douglas Pleskow, Jonah Cohen, \\ Tyler M. Berzin
}

Institution

Center for Advanced Endoscopy, Division of

Gastroenterology, Beth Israel Deaconess Medical Center and Harvard Medical School, Boston, Massachusetts, United States

submitted 9.8.2019

accepted after revision 7.10 .2019

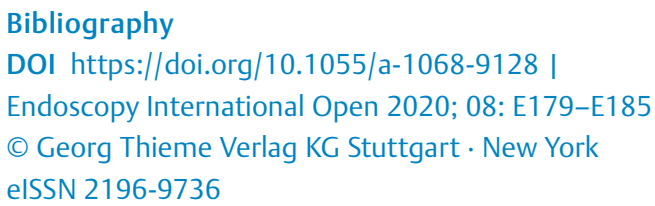

Corresponding author

Tyler M. Berzin, MD, Beth Israel Deaconess Medical Center, Harvard Medical School, 330 Brookline Avenue, Rabb-Rose 101, Boston, MA 02215

Fax: +1-617-667-1171

tberzin@bidmc.harvard.edu

\section{ABSTRACT}

Background and study aims Chemoradiation with stereotactic body radiation therapy (SBRT) is increasingly being used for optimal treatment of locally advanced pancreatobiliary cancers. Fiducial markers are used to track these tumors during SBRT. Endoscopic ultrasound (EUS) is the preferred route for fiducial marker placement for ease of access to pancreatobiliary structures and accurate placement. Here we evaluate the safety and infection risk associated with EUS-guided fiducial placement for pancreatobiliary malignancies and use of peri-procedural prophylactic antibiotics.

Patients and methods This was a retrospective, singlecenter study including consecutive patients presenting for EUS-guided fiducial placement in pancreatobiliary region by three expert interventional endoscopists for SBRT from July 2010 to February 2018 at a tertiary care center. Patient demographics, tumor characteristics, EUS technique, fiducials, use of prophylactic antibiotics, adverse events (AEs) and SBRT/Cyberknife administration were reported.

Results A total of 355 patients with pancreatobiliary malignancy underwent EUS-guided fiducial placement, of whom 308 patients (86.76\%) successfully underwent SBRT. Of the patients, 304 (85.63\%) received peri-procedural prophylactic antibiotic. Of 355 total patients, 5.9\% $(n=21)$ were noted to develop AEs (mild to severe) with no significant difference in incidence of infection with or without use of peri-procedural prophylactic antibiotic. Only three patients developed infectious AEs, none of which were definitively related to fiducial placement.

Conclusion EUS-guided fiducial placement for pancreatobiliary malignancy is safe and efficacious, and risk of infection is rare, regardless of whether or not peri-procedural antibiotics are used. We favor limiting routine use of periprocedural antibiotics for patients undergoing EUS-guided fiducial placement in pancreaticobiliary malignancy.

\section{Introduction}

Pancreatic and bile duct cancers remain devastating diagnoses with 5 -year survival rates of only $8 \%$ to $10 \%[1,2]$. These malignancies are generally diagnosed at a later stage and for this reason, surgery as initial management is a consideration in only a small minority of cases. Optimal treatment of locally advanced pancreatobiliary malignancies is evolving rapidly and the role of chemotherapy alone vs. chemoradiation is the topic of ongoing investigation $[3,4]$, with many centers offering chemoradiation as the first-line option.

Stereotactic body radiation therapy (SBRT) is increasingly being used as an alternative to conventional radiation therapy. This is because of the potential of SBRT to provide a higher combined dose of radiation over fewer treatments for pancreaticobiliary cancers and other malignancies [5, 6]. SBRT requires highly precise targeting of the tumor tissue and for this reason, 
many SBRT protocols require the placement of fiducial markers in or near the tumor.

Fiducials have been proven to be better surrogate markers for tumor position than stents or other anatomical landmarks [7]. Fiducial markers were originally placed intraoperatively or percutaneously under radiologic guidance [8-10]. Endoscopic ultrasound has now assumed a dominant role for fiducial placement due to its close proximity to pancreatobiliary structures, offering improved access to pancreaticobiliary anatomy and other Gl structures [11-13]. Data on safety and efficacy, however, still remain fairly limited. In addition, use of antibiotics during EUS-guided fiducial placement varies in clinical practice and the benefit remains unknown. The goal of the current study was to assess the safety and efficacy of EUS-guided fiducial placement in a large single-center series, as well as to assess risk of infection in patients undergoing fiducial placement with and without peri-procedural antibiotics.

\section{Patients and methods}

We performed a retrospective, single-center study of consecutive patients who underwent EUS-guided fiducial placement by three expert interventional endoscopists from July 2010 to February 2018 at a tertiary care hospital. All patients underwent EUS with linear echoendoscope (Olympus Corporation, Center Valley, Pennsylvania, United States). Based on availability and endoscopist preference, either a 19-gauge (Wilson Cook Medical, Winston-Salem, North Carolina, United States; Beacon Endoscopy/Medtronic Inc, Sunnyvale, California, United States) fine-needle aspiration (FNA) needle loaded with $0.8 \times 3-\mathrm{mm}$ gold fiducial or a preloaded 22-gauge fiducial needle (Beacon Endoscopy/Medtronic Inc, Sunnyvale, California, United States) with $0.43 \times 5-\mathrm{mm}$ gold fiducial were used for placement. For the standard $19 \mathrm{~g}$ FNA needle, one fiducial was loaded at a time, with bone wax to fix the fiducial in place prior to deployment, and a new fiducial had to be loaded after each needle pass. The dedicated 22-gauge fiducial needle is pre-loaded with two fiducials, and a second pre-loaded needle was used for placement of additional fiducials. Standard EUS approaches using Doppler guidance were used to place fiducials in and around the target tissue, with the goal of placing more than two fiducials when feasible. The decision to use prophylactic antibiotics was at the discretion of the endoscopist.

Patient demographics, EUS technical details, tumor characteristics, co-morbidities, prophylactic antibiotic use, adverse events (AEs) and administration of SBRT/Cyberknife were recorded. The pattern of prophylactic antibiotic use was categorized as pre-procedural (IV single dose), post-procedural (oral, for 3-7 days), or both.

AEs were categorized as mild, moderate and severe based on the American Society for Gastrointestinal Endoscopy (ASGE) lexicon for endoscopy events [14]. Moderate and severe AEs included major bleeding requiring blood transfusion, cholangitis, bacteremia (positive blood cultures), pancreatitis and septic shock. Mild AEs included pain, fever, transaminitis (ALT and/or AST $>3 \times$ upper limit of normal) and minor bleeding not requiring transfusion.
Analysis was performed using SPSS software. Chi-square test was used to test for statistical significance and a two tailed $P<$ 0.05 was considered statistically significant. Test of Pearson Correlation was used with the correlation coefficient comprised between -1 and 1 where -1 indicates strong negative correlation, 1 indicates strong positive correlation and 0 indicates no association between the two variables. The study was approved by the local Institutional Review Board.

\section{Results}

A total of 355 patients underwent EUS-guided fiducial placement, with an age range between 34 and 92 years (mean age 68.5 years). Of them, 181 patients (51\%) were male and 174 (49\%) were female. The most common diagnosis was pancreatic adenocarcinoma $(n=299,84.2 \%)$ followed by cholangiocarcinoma $(n=16)$, renal cell carcinoma with pancreatic metastases $(n=10)$, and hepatocellular carcinoma $(n=7)(\triangleright$ Table 1$)$. The majority of tumors were located in the head of the pancreas $(n=207,58.3 \%)$.

A total of 1186 fiducials were placed with a range of one to four fiducials per patient (mean of 3.33). Fiducials were placed using a 19-gauge FNA needle in $61 \%$ patients $(n=211)$ and with a preloaded 22 -gauge fiducial needle in $39 \%$ patients $(n=136)$. Of the 355 patients, 304 (85.63\%) received prophylactic antibiotic and 51 (14.37\%) did not. Among patients who received antibiotics, 107 received only pre-procedural antibiotic, 32 received only post-procedure antibiotics, and 165 received antibiotics both pre- and post-procedure.

Of the total 355 patients, 308 (86.76\%) patients underwent SBRT successfully. Eighteen patients were lost to follow-up or transitioned to other facilities, 17 patients had interval disease progression, seven died before SBRT, three declined treatment, and one patient had an initial diagnosis of malignancy changed to a benign diagnosis. One patient could not undergo SBRT due to inability of the Cyberknife system to track the fiducials. This patient underwent an initial SBRT session 13 days after four fiducial markers were placed at the borders of a 3.9-cm pancreatic head adenocarcinoma. The SBRT session was aborted after $10 \%$ of targeted treatment. Review of the patient's inspiration/ expiration scans revealed significant torsional motion of the target with breathing. In addition, the fiducials were noted to be located at the top of the target volume in a cluster, making tracking less reliable.

Twenty-one of 355 patients (5.9\%) developed procedural AEs ( $\triangleright$ Table 2 ). Three patients developed acute pancreatitis, although two of them had undergone same-session ERCP. One patient had major bleeding requiring blood transfusion after EUS-guided fiducial placement. One of 51 patients (2\%) with no antibiotic use developed acute cholangitis, whereas two of $304(0.7 \%)$ with prophylactic antibiotic use developed bacteremia and septic shock respectively. Importantly, only one patient had a definitive biliary source (cholangitis likely secondary to biliary stent displacement), while the other two patients had other likely sources of sepsis including pneumonia and Clostridium difficile. In any case, occurrence of moderate to severe infectious AEs (bacteremia, acute cholangitis and septic shock) 
- Table 1 Patient characteristics and indication of fiducial placement.

\begin{tabular}{|c|c|c|}
\hline & & $\mathrm{N}(\%)$ \\
\hline \multirow[t]{2}{*}{ Gender } & Males & $181(51 \%)$ \\
\hline & Females & $174(49 \%)$ \\
\hline Age & Mean & $\begin{array}{l}68.5(34- \\
92 \text { years })\end{array}$ \\
\hline \multirow[t]{15}{*}{ Cancer } & Pancreatic adenocarcinoma & 298 \\
\hline & Cholangiocarcinoma & 16 \\
\hline & RCC with pancreatic metastases & 10 \\
\hline & Hepatocellular carcinoma & 7 \\
\hline & Pancreatic neuroendocrine tumor & 5 \\
\hline & Esophageal carcinoma & 4 \\
\hline & Gall bladder carcinoma & 3 \\
\hline & Ampullary carcinoma & 3 \\
\hline & Stomach adenocarcinoma & 2 \\
\hline & $\begin{array}{l}\text { Metastatic melanoma with peripan- } \\
\text { creatic mass at portal confluence }\end{array}$ & 1 \\
\hline & $\begin{array}{l}\text { Intraductal papillary mucinous Neo- } \\
\text { plasm with malignant transformation }\end{array}$ & 2 \\
\hline & SCC metastases in head of pancreas & 1 \\
\hline & $\begin{array}{l}\text { Prostate cancer with metastases in } \\
\text { head of pancreas }\end{array}$ & 1 \\
\hline & $\begin{array}{l}\text { Ovarian cancer with metastases in } \\
\text { head of pancreas }\end{array}$ & 1 \\
\hline & Colon cancer with liver metastases & 1 \\
\hline \multirow{3}{*}{$\begin{array}{l}\text { Tumor } \\
\text { consis- } \\
\text { tency }\end{array}$} & Solid & 343 \\
\hline & Cystic & 3 \\
\hline & Mixed & 9 \\
\hline \multirow{2}{*}{$\begin{array}{l}\text { Tumor } \\
\text { size }\end{array}$} & Average size & $2.86 \mathrm{~cm}$ \\
\hline & III-defined masses (n) & 49 \\
\hline
\end{tabular}

RCC, renal cell carcinoma; SCC, squamous cell carcinoma.

was rare and not statistically significantly different between the two groups, nor was post-procedure fever, with or without use of peri-procedural antibiotics ( $\$$ Table 3 and $\triangleright$ Table 4 ).

There was no significant correlation between infection risk and type of tumor (solid, cystic or mixed) $(r=0.12)$, location of tumor $(r=0.124)$, type of needle used $(r=-.036)$ or recent chemotherapy ( $r=0.029)$. Additionally, number of fiducials placed (1-6) and needle gauge (19-g vs. 22-g) did not correlate with risk of mild or moderate-severe AEs.

\section{Discussion}

Our study demonstrates that EUS-guided fiducial placement is safe and feasible for pancreaticobiliary malignancy. AEs, including infectious AEs, are exceedingly rare. To our knowledge, this is the largest study to date evaluating the safety and efficacy of EUS-guided fiducial placement for pancreatobiliary and associated malignancies.

Despite the large sample size, the benefit of prophylactic antibiotics was not significant statistically and perhaps would require an even larger study population and a randomized design to illustrate. We did not find any significant correlation between infectious AEs and tumor type, location, type of needle used or recent chemotherapy. It is worth also carefully considering the patients in whom infection did develop, as only one of three had a definitive biliary source. In the one patient who developed cholangitis (without prophylactic antibiotics during fiducial placement), the patient had a diagnosis of ampullary cancer, with a plastic biliary stent in place prior to EUS. The patient presented with cholangitis several days after fiducial placement and was found to have displacement of the previously placed plastic stent. Given that the fiducials were placed in the vicinity of the stent, it is possible that fiducial placement may have inadvertently contributed to stent displacement and/or contributed directly to bacterial seeding of the bile duct. One patient who presented with sepsis and did receive prophylactic preand post-procedure antibiotic had undergone same session ERCP with stent exchange, along with EUS-guided fiducial placement. This patient was readmitted 2 days later with septic shock, slightly elevated bilirubin levels, and evidence of pneumonia, and was transitioned to comfort care before additional diagnostic steps could be taken. The third patient with a potentially-related infection had received a single pre-procedural dose of intravenous antibiotics before fiducial placement and was hospitalized 10 days after EUS with fever and Escherichia coli bacteremia and was diagnosed with concurrent $C$. difficile.

On review of literature, we identified only three reports of infectious AEs (cholangitis) with EUS-guided fiducial placement for intra-abdominal malignancies, and all were in patients who had not received peri-procedural antibiotics [15-17]. In the available studies published in which patients received prophylactic antibiotics $[9,12,13,16-24]$ ( $\triangleright$ Table 5), no infectious AEs were reported in our review.

There are no clear guidelines on use of antibiotic prophylaxis in EUS-guided fiducial placement. The American Society of Gastrointestinal Endoscopy recommends against antibiotic prophylaxis before diagnostic EUS or EUS-FNA of solid lesions of the gastrointestinal tract and suggests their use before diagnostic FNA of cystic lesions [25]. Results of the current study, along with the prior smaller studies referenced above, suggest that infection after fiducial placement is exceedingly rare. In our own large study, there was only one definitive biliary infection (likely due to stent displacement) in a patient who had not received prophylactic antibiotics, and two patients with several possible infections including, respectively, pneumonia and C. difficile, who both received antibiotics. 
- Table 2 Characteristics of fiducial placement, concurrent bile stent, chemotherapy and antibiotic use.

\begin{tabular}{|c|c|c|}
\hline & & $\mathbf{N}(\%)$ \\
\hline \multirow[t]{2}{*}{ Fiducials } & Total number placed & 1186 \\
\hline & Average no.per patient & 3.33 (1-4; only 1 patient had 6 placed) \\
\hline \multirow[t]{2}{*}{ Needle type } & $19 \mathrm{~g}$ & $211(60.8 \%)$ \\
\hline & $22 \mathrm{~g}$ & $136(39.2 \%)$ \\
\hline \multirow[t]{17}{*}{ Location of fiducial placement } & Pancreatic head & $207(58.3 \%)$ \\
\hline & Body & $56(15.8 \%)$ \\
\hline & Neck & $21(5.9 \%)$ \\
\hline & Uncinate process & $15(4.2 \%)$ \\
\hline & Tail & $9(2.5 \%)$ \\
\hline & Porta hepatis & $8(2.3 \%)$ \\
\hline & Common bile duct mass & $5(1.4 \%)$ \\
\hline & Gastro-hepatic lymph nodes & 4 \\
\hline & Pancreatic tumor bed s/p Whipple's & 3 \\
\hline & Liver & 3 \\
\hline & Para-esophageal lymph nodes & 3 \\
\hline & Gall bladder & 3 \\
\hline & Celiac lymph nodes & 2 \\
\hline & Head, neck and body & 2 \\
\hline & Body and tail & 1 \\
\hline & Neck and uncinate process & 1 \\
\hline & Others & $12(3.4 \%)$ \\
\hline \multirow[t]{2}{*}{ Presence of bile duct stents } & Yes & $167(47 \%)$ \\
\hline & No stents & $188(53 \%)$ \\
\hline \multirow[t]{4}{*}{ Antibiotic pattern } & Pre- and post-procedure & $165(46.5 \%)$ \\
\hline & Pre-procedure & $107(30.1 \%)$ \\
\hline & Post-procedure & $32(9.1 \%)$ \\
\hline & No antibiotics & $51(14.4 \%)$ \\
\hline \multirow[t]{3}{*}{ Endoscopists } & Attending 1 & $111(31.3 \%)$ \\
\hline & Attending 2 & $163(45.9 \%)$ \\
\hline & Attending 3 & $81(22.8 \%)$ \\
\hline \multirow[t]{2}{*}{ Cyber-knife therapy } & Yes & $308(86.76 \%)$ \\
\hline & No & $47(13.24 \%)$ \\
\hline \multirow[t]{2}{*}{ Chemotherapy } & Within 2 weeks before or after procedure & $176(49.6 \%)$ \\
\hline & No chemotherapy & $179(50.4 \%)$ \\
\hline \multirow[t]{3}{*}{ Adverse Events (AEs) } & Present & $21(5.9 \%)$ \\
\hline & Absent & $334(94.1 \%)$ \\
\hline & Infectious AEs (excluding fever with no confirmed source) & $3 / 355(0.84 \%)$ \\
\hline
\end{tabular}




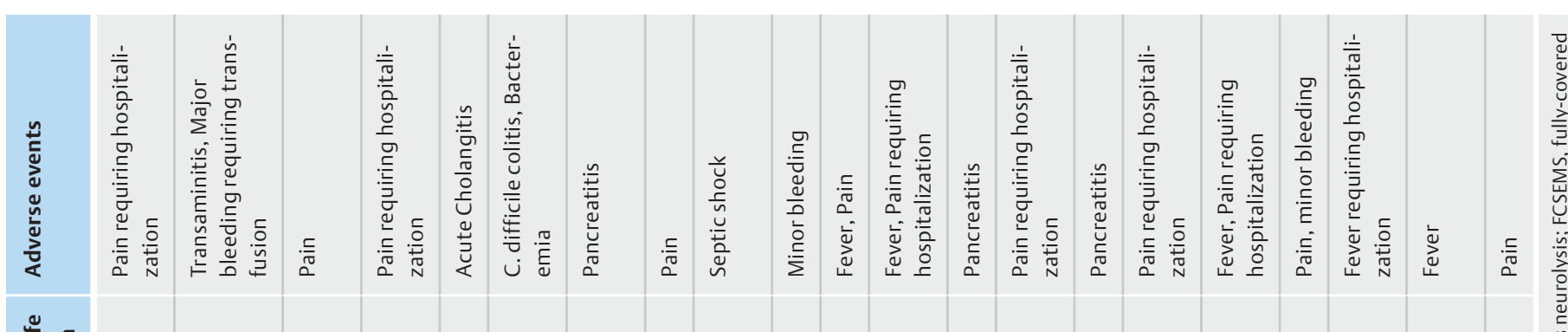

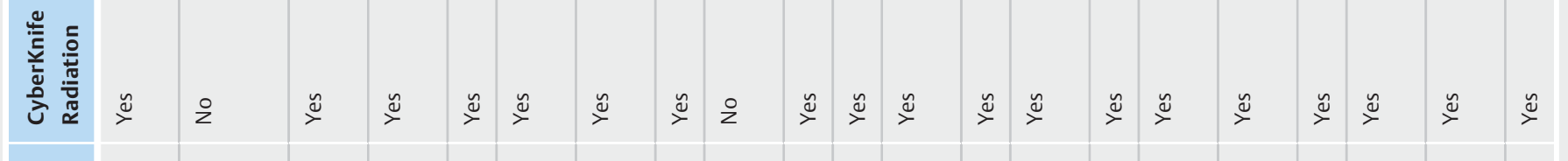

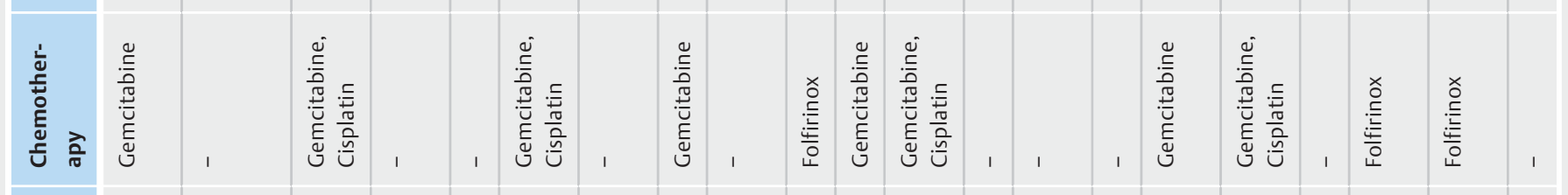

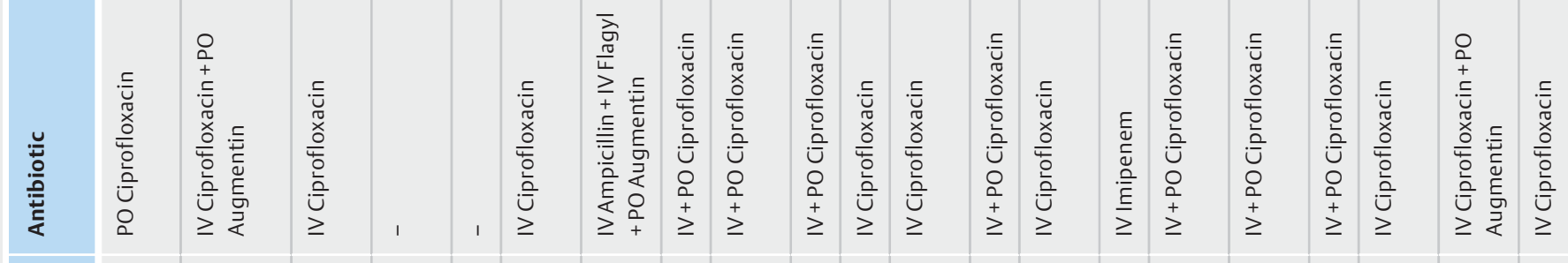
蒿

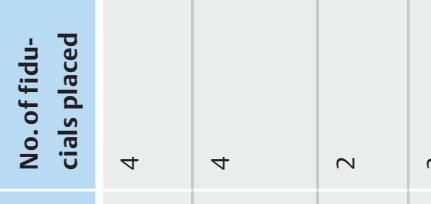

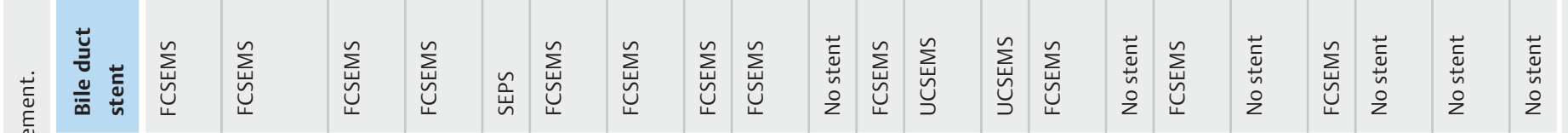
彭

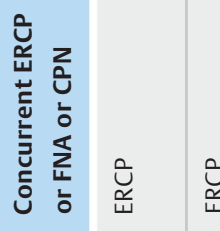

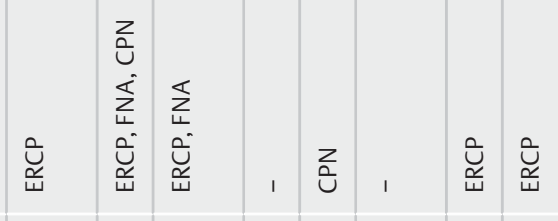

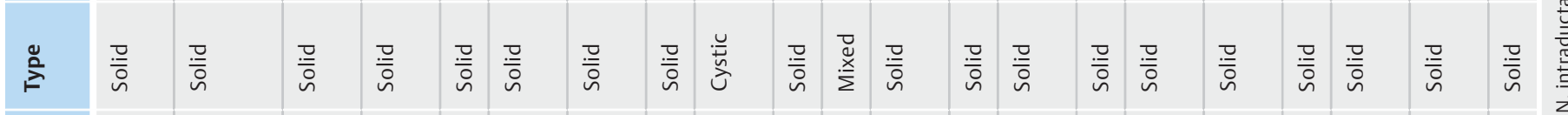

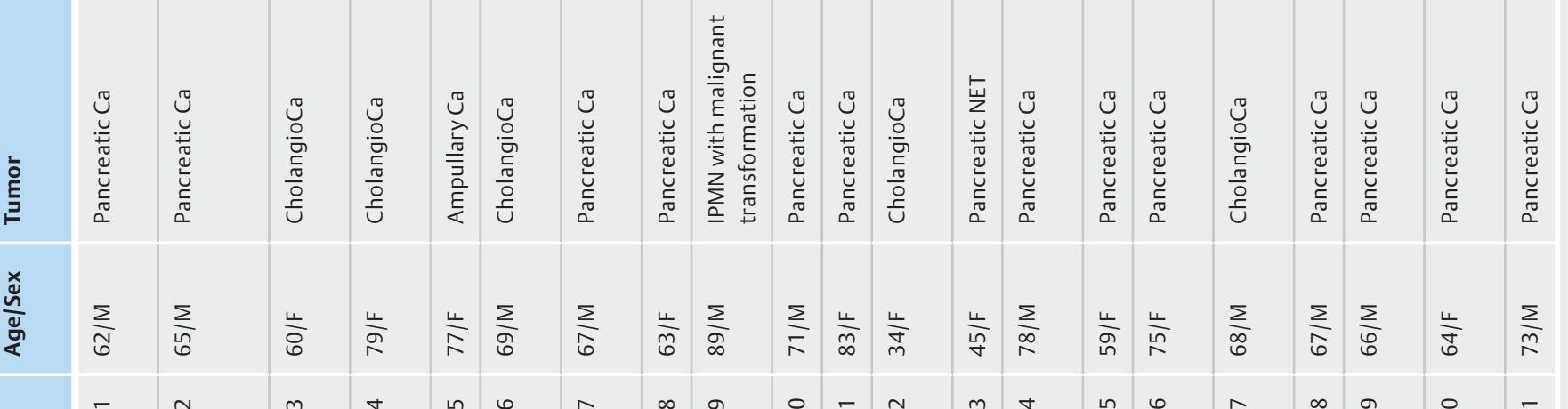

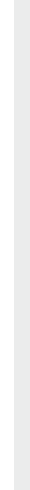

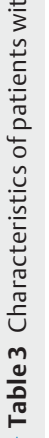


- Table4 Statistical significance of use of prophylactic antibiotics and infectious adverse events.

\begin{tabular}{|l|l|l|l|}
\hline & $\begin{array}{l}\text { Antibiotic } \\
\text { used }\end{array}$ & $\begin{array}{l}\text { No antibiotic } \\
\text { used }\end{array}$ & $\begin{array}{l}\text { P value } \\
\text { (significant <0.05) }\end{array}$ \\
\hline $\begin{array}{l}\text { Major } \\
\text { Infections }\end{array}$ & $1 / 51$ & $2 / 304$ & 0.35 \\
\hline Fever & $2 / 51$ & $6 / 304$ & 0.32 \\
\hline
\end{tabular}

The major limitations of our study include the retrospective nature of data collection, selective and non-randomized use of antibiotics, and low rate of AEs, including infectious. It is possible that our study was underpowered to detect important risk factors for infection and other AEs after EUS-guided fiducial placement. However, this study accounts for the largest number of patients undergoing EUS-guided fiducial placement for pancreatobiliary malignancies to date. There was $100 \%$ clinical success in fiducial placement with a low rate of mild to severe
AEs and no significant difference in occurrence of infectious AEs, with or without use of prophylactic antibiotics. It is our opinion that fiducial placement in or near a cystic mass, and fiducial placement in or near a biliary stricture which may not be adequately drained, are both scenarios where infection risk could be reasonably judged to be higher, and for which prophylactic antibiotic use could be favored on an individual basis. This selective approach derives more from guidelines and experience on the management of cystic lesions and bile duct interventions, rather than strong evidence in our study or any prior data on fiducial placement specifically.

\section{Conclusion}

EUS-guided fiducial placement for pancreatobiliary malignancy is safe and efficacious, and risk of infection is rare, regardless of whether or not peri-procedural antibiotics are used. For most patients, we recommend against routine use of antibiotics for EUS-guided fiducial placement for three reasons: 1 ) infectious AEs are exceedingly rare in this setting; 2 ) there are no data to

- Table 5 Safety and efficacy of EUS-guided fiducial placement in pancreatobiliary malignancies.

\begin{tabular}{|c|c|c|c|c|c|}
\hline Study & Type of study & $\begin{array}{l}\text { Number of pancreato- } \\
\text { biliary cases }\end{array}$ & $\begin{array}{l}\text { Prophylactic anti- } \\
\text { biotic use } \mathrm{N}(\%)\end{array}$ & $\begin{array}{l}\text { Technical } \\
\text { success N (\%) }\end{array}$ & Adverse events (n) \\
\hline $\begin{array}{l}\text { Pishvaian et al } \\
\text { (2006) [16] }\end{array}$ & Prospective & 13 & $5(38.5 \%)$ & $11(85 \%)$ & Cholangitis (1) \\
\hline $\begin{array}{l}\text { Kothary et al } \\
\text { (2009) [9] }\end{array}$ & Retrospective & 95 & Not reported & $94(97.9 \%)$ & $\begin{array}{l}\text { Minor bleeding (3), fiducial migration } \\
\text { (2) }\end{array}$ \\
\hline $\begin{array}{l}\text { Varadarajulu } \\
\text { et al (2010) [19] }\end{array}$ & Retrospective & 9 & None & $9(100 \%)$ & None \\
\hline $\begin{array}{l}\text { Park et al (2010) } \\
{[20]}\end{array}$ & Prospective & 57 & $57(100 \%)$ & $56(98 \%)$ & Minor bleeding (1) \\
\hline $\begin{array}{l}\text { Sanders et al } \\
(2010)[12]\end{array}$ & Prospective & 51 & $51(100 \%)$ & $46(90 \%)$ & Mild pancreatitis (1) \\
\hline $\begin{array}{l}\text { Ammar et al } \\
(2010)[21]\end{array}$ & Case Series & 13 & $13(100 \%)$ & $13(100 \%)$ & None \\
\hline $\begin{array}{l}\text { Khashab et al } \\
\text { (2012) [22] }\end{array}$ & Retrospective & 39 & $39(100 \%)$ & $39(100 \%)$ & None \\
\hline $\begin{array}{l}\text { Dimaio et al } \\
\text { (2010) [17] }\end{array}$ & Retrospective & $\begin{array}{l}10 \text { (remaining } 20 \text { cases } \\
\text { were esophageal) }\end{array}$ & $\begin{array}{l}6 \text { (out of total } \\
30 \text { cases) }\end{array}$ & $10(100 \%)$ & $\begin{array}{l}\text { Fever with transaminitis (1) (No pro- } \\
\text { phylactic antibiotic) }\end{array}$ \\
\hline $\begin{array}{l}\text { Majumdar et al } \\
\text { (2013) [13] }\end{array}$ & Retrospective & 39 (out of total 77) & $39(100 \%)$ & $39(100 \%)$ & $\begin{array}{l}\text { Pain (3), mild pancreatitis (1), fiducial } \\
\text { migration (4) }\end{array}$ \\
\hline $\begin{array}{l}\text { Choi et al (2014) } \\
\text { [23] }\end{array}$ & Retrospective & 32 & $32(100 \%)$ & $32(100 \%)$ & Mild pancreatitis (1) \\
\hline $\begin{array}{l}\text { Dhadham et al } \\
(2016)[18]\end{array}$ & Retrospective & 188 & Not reported & $187(99.5 \%)$ & $\begin{array}{l}\text { Minor bleeding (7), fiducial migration } \\
\text { (3) }\end{array}$ \\
\hline $\begin{array}{l}\text { Machicado et al } \\
(2019)[24]\end{array}$ & Prospective & 44 & Not reported & $42(95.5 \%)$ & Pain (19), Nausea and/or vomiting (9) \\
\hline Current study & Retrospective & 355 & $304(85.6 \%)$ & $355(100 \%)$ & $\begin{array}{l}\text { Pain (7), fever (5), minor ( } 2 \text { ) and } \\
\text { major bleeding ( } 1 \text {, pancreatitis ( } 3 \text {, } \\
\text { cholangitis ( } 1 \text { ), Bacteremia (1), } \\
\text { septic shock (1) }\end{array}$ \\
\hline
\end{tabular}


suggest that routine use of antibiotics meaningfully reduces risk of these events; and 3) routine antibiotic use may expose patients to medication-related AEs and contribute to antibiotic resistance.

\section{Competing interests}

Dr. Berzin and Dr. Pleskow have received consulting and speaking fees from Medtronic and Boston Scientific.

\section{References}

[1] Cancer Facts and Figures 2019. Atlanta, Ga: 2019: Available from: https://www.cancer.org/content/dam/cancer-org/research/cancerfacts-and-statistics/annual-cancer-facts-and-figures/2019/cancerfacts-and-figures-2019.pdf [Accessed 2019 Jun 9]

[2] Cancer Facts and Figures 2018. Atlanta, Ga: 2018: Available from: https://www.cancer.org/content/dam/cancer-org/research/cancerfacts-and-statistics/annual-cancer-facts-and-figures/2018/cancerfacts-and-figures-2018.pdf [Accessed 2019 Jun 9]

[3] Willett CG, Czito BG, Bendell JC et al. Locally advanced pancreatic cancer. J Clin Oncol 2005; 23: 4538-4544

[4] Choi Y, Kim T-Y, Oh D-Y et al. Comparison of concurrent chemoradiotherapy and chemotherapy alone for locally advanced pancreatic cancer. J Clin Oncol 2014; 32: 351-351

[5] Chang DT, Schellenberg D, Shen J et al. Stereotactic radiotherapy for unresectable adenocarcinoma of the pancreas. Cancer 2009; 115: $665-672$

[6] Comito T, Cozzi L, Clerici E et al. Can stereotactic body radiation therapy be a viable and efficient therapeutic option for unresectable locally advanced pancreatic adenocarcinoma? results of a phase 2 study Technol Cancer Res Treat 2017; 16: 295-301

[7] van der Horst A, Lens E, Wognum S et al. Limited role for biliary stent as surrogate fiducial marker in pancreatic cancer: stent and intratumoral fiducials compared. Int ] Radiat Oncol Biol Phys 2014; 89: 641648

[8] Shirato H, Harada T, Harabayashi T et al. Feasibility of insertion/implantation of 2.0-mm-diameter gold internal fiducial markers for precise setup and real-time tumor tracking in radiotherapy. Int J Radiat Oncol Biol Phys 2003; 56: 240-247

[9] Kothary N, Heit JJ, Louie JD et al. Safety and efficacy of percutaneous fiducial marker implantation for image-guided radiation therapy. J Vasc Interv Radiol 2009; 20: 235-239

[10] Kim JH, Hong SS, Kim JH et al. Safety and Efficacy of UltrasoundGuided Fiducial Marker Implantation for CyberKnife Radiation Therapy. Korean J Radiol 2012; 13: 30-313
[11] Chavalitdhamrong D, DiMaio C], Siersema PD et al. Technical advances in endoscopic ultrasound-guided fiducial placement for the treatment of pancreatic cancer. Endosc Int Open 2015; 3: E373-E377

[12] Sanders MK, Moser AJ, Khalid A et al. EUS-guided fiducial placement for stereotactic body radiotherapy in locally advanced and recurrent pancreatic cancer. Gastrointest Endosc 2010; 71: 1178-1184

[13] Majumder S, Berzin TM, Mahadevan A et al. Endoscopic ultrasoundguided pancreatic fiducial placement. Pancreas 2013; 42: 692-695

[14] Cotton PB, Eisen GM, Aabakken L et al. A lexicon for endoscopic adverse events: report of an ASGE workshop. Gastrointest Endosc 2010; 71: 446-454

[15] Varadarajulu S. Antibiotic prophylaxis is recommended for endoscopic ultrasound-guided fiducial placements. J Clin Gastroenterol 2011; 45: 179

[16] Pishvaian AC, Collins B, Gagnon G et al. EUS-guided fiducial placement for CyberKnife radiotherapy of mediastinal and abdominal malignancies. Gastrointest Endosc 2006; 64: 412-417

[17] DiMaio C], Nagula S, Goodman KA et al. EUS-guided fiducial placement for image-guided radiation therapy in $\mathrm{Gl}$ malignancies by using a 22-gauge needle (with videos). Gastrointest Endosc 2010; 71: $1204-1210$

[18] Dhadham G, Hoffe S, Harris C et al. Endoscopic ultrasound-guided fiducial marker placement for image-guided radiation therapy without fluoroscopy: safety and technical feasibility. Endosc Int Open 2016; 4: E378-E382

[19] Varadarajulu S, Trevino J, Shen S et al. The use of endoscopic ultrasound-guided gold markers in image-guided radiation therapy of pancreatic cancers: a case series. Endoscopy 2010; 42: 423-425

[20] Park WG, Yan BM, Schellenberg D et al. EUS-guided gold fiducial insertion for image-guided radiation therapy of pancreatic cancer: 50 successful cases without fluoroscopy. Gastrointest Endosc 2010; 71 : 513-518

[21] Ammar T, Coté GA, Creach KM et al. Fiducial placement for stereotactic radiation by using EUS: feasibility when using a marker compatible with a standard 22-gauge needle. Gastrointest Endosc 2010; 71: 630-633

[22] Khashab MA, Kim KJ, Tryggestad E] et al. Comparative analysis of traditional and coiled fiducials implanted during EUS for pancreatic cancer patients receiving stereotactic body radiation therapy. Gastrointest Endosc 2012; 76: 962-971

[23] Choi J-H, Seo D-W, Park DH et al. Fiducial placement for stereotactic body radiation therapy under only endoscopic ultrasonography guidance in pancreatic and hepatic malignancy: practical feasibility and safety. Gut Liver 2014; 8: 88-93

[24] Machicado JD, Obuch JC, Goodman KA et al. Endoscopic ultrasound placement of preloaded fiducial markers shortens procedure time compared to back-loaded markers. Clin Gastroenterol Hepatol 2019; 17: 2749-2758.e2

[25] Khashab MA, Chithadi KV, Acosta RD et al. Antibiotic prophylaxis for Gl endoscopy. Gastrointest Endosc 2015; 81: 81-89 